\title{
DEFICIÊNCIA MENTAL E FAMÍLIA: UMA ANÁLISE DA PRODUÇÃO CIENTÍFICA ${ }^{1}$
}

\author{
Maria Auxiliadora Dessen ${ }^{2}$ \\ Nara Liana Pereira Silva
}

RESUMO: A produção científica na área de deficiência mental tem aumentado nos últimos anos, porém, ainda é escassa. Este estudo tem como objetivo analisar resumos de publicações científicas na área de deficiência mental e família, referentes ao período de 1985 a 1999, focalizando os temas investigados, o tamanho da amostra e as técnicas empregadas para a coleta de dados. Foi realizado um levantamento no Psychological Abstracts, nas bases de dados PsycLit e ProQuest e nos principais periódicos nacionais. Foram encontradas 304 publicações diretamente relacionadas ao assunto, sendo $38 \%$ artigos de pesquisa, $21 \%$ artigos teóricos/revisão de literatura, 20,4\% livros/capítulos de livros, $10 \%$ teses/dissertações e $7,2 \%$ resenhas/ comentários. Verificou-se que $44 \%$ dos artigos de pesquisa utilizaram apenas uma técnica para a coleta de dados, sendo a observação do comportamento a técnica mais empregada. Os resultados mostram que há necessidade de se estudar as famílias de crianças com deficiência mental, focalizando as interações e relações desenvolvidas entre os diferentes subsistemas familiares e, também, a importância de se adotar a teoria dos sistemas ecológicos de Bronfenbrenner para o desenvolvimento de projetos de pesquisa nesta área.

Palavras-chave: produção científica; deficiência mental; família; interações genitores-criança; crianças pré-escolares.

\section{ANALISYS OF RESEARCH IN MENTAL DEFICIENCY AND FAMILY}

ABSTRACT: The literature on mental deficiency has increased in the recent years, although it is still scarce. This study aims to analyse abstracts of scientific publications in the mental deficiency and family area, from 1985 to 1999, focusing on research themes, size of samples, and techniques used for data collection. This analysis was based on the following sources: Psychological Abstracts, PsycLit, ProQuest and some of the main Brazilian journals of psychology. We found 304 publications directly related to this subject classified into research articles (38\%), theoretical and review articles (21\%), books and books chapters $(20,4 \%)$, master's theses and doctoral dissertations $(10 \%)$, and technical notes and reviews of books $(7,2 \%)$. The results show us that $44 \%$ of the research articles employed only one technique for data collection, mainly behaviour observation. We conclude that it is necessary to study families of mental retardation children focusing on social interactions and relationships among different family subsystems. In addition, it could be very helpful to implement research adopting Bronfenbrenner's ecological systems theory to better understand the family development of mental retardation children.

Key words: research; mental deficiency; family; parent-child interactions; preschoolers.

O conceito de deficiência mental tem uma relação estreita com as concepções sócio-econômicas e ideais que nortearam cada período da história do homem. Conhecer essas idéias é, também, compreender mais acerca da deficiência mental, o que

\footnotetext{
${ }^{1}$ Artigo recebido para publicação em $08 / 00$; aceito em $06 / 01$

${ }^{2}$ Endereço para correspondência: Maria Auxiliadora Dessen, Laboratório de Desenvolvimento Familiar, Instituto de Psicologia, Universidade de Brasília, Campus Universitário, Brasília-DF, Cep 70910-900, e-mail dessen@unb.br
}

propicia maior clareza sobre este conceito, o que, por sua vez, constitui o primeiro passo para a implementação de serviços de atendimento a esta clientela e de projetos de pesquisa na área. Assim, este artigo apresenta um panorama geral sobre o conceito de deficiência mental $\mathrm{e}$ sobre $\mathrm{o}$ atendimento às crianças deficientes, tecendo comentários sobre a importância da família para o desenvolvimento de tais crianças. Em seguida, são descritos o método empregado para o levantamento da literatura nacio-

Paidéia, FFCLRP-USP, Rib. Preto, ago/dez/2000. 
nal e estrangeira sobre deficiência mental e família e o resultado da análise dos resumos da produção cientifica relativa aos seguintes temas: 1) conceito de deficiência mental (DM), 2) família e sua criança deficiente mental (DM) e 3) interações sociais, tanto no contexto familiar como em outros contextos. Nesta análise, foram incluídos os temas mais investigados e a identificação do tamanho da amostra e das técnicas empregadas para a coleta de dados, em se tratando de estudos empíricos. Esperamos, assim, fornecer um panorama da área, focalizando, particularmente, as interações e as relações familiares.

\section{Conceituação de deficiência mental: um breve histórico}

Pessoti (1984) faz uma revisão histórica a respeito da deficiência mental, destacando as concepções adotadas, em cada período, que influenciaram as atitudes da sociedade em relação à deficiência. Aranha (1991) também se reporta à história para descrever como a integração social do deficiente foi associada à concepção de deficiência, a qual merece destaque. Na sociedade antiga, as crianças deficientes eram deixadas ao relento para que morressem. Essa atitude era fruto dos ideais morais da época em que a eugenia e a perfeição do indivíduo eram considerados valores preponderantes. Já no final do século $\mathrm{XV}$, com os ideais burgueses vigentes nesse período, imperou a visão de que a deficiência era um atributo do indivíduo, tendo, portanto, uma relação direta com o capital, ou seja, o deficiente era considerado improdutivo, do ponto de vista econômico (Aranha, 1991, 1995; Glat, 1995; Schwartzman, 1999a, 1999b).

Com o passar dos séculos, as concepções sobre DM foram se ampliando, em parte como consequiência das mudanças ocorridas nas sociedades e no campo científico. Mas, foi somente no século XIX que se percebeu uma postura de responsabilidade pública com relação às necessidades dos deficientes. No século XX, as ações se tornaram mais concretas, havendo uma multiplicidade de modos de encarar a DM, acarretando o surgimento de vários modelos explicativos ${ }^{3}$, como o metafísico, o médico, o educacional, o da determinação social e o só-

\footnotetext{
${ }^{3}$ Detalhes sobre tais modelos podem ser encontrados em Nunes e Ferreira (1994).
}

Paidéia, FFCLRP-USP, Rib. Preto, ago/dez/2000. cio-construtivista ou sócio-histórico (Aranha, 1995). Para esta autora, a deficiência mental deve ser encarada como uma construção social, não alheia à concepção de homem e de sociedade vigentes e deve ser tratada como um fenômeno multideterminado. Contudo, segundo Nunes \& Ferreira (1994), a DM ainda continua sendo considerada como estando dentro do indivíduo, descontextualizada e sem nexo social como mostra o discurso da maior parte dos órgãos públicos.

A conceituação e caracterização da DM adotada no Brasil pelo Ministério da Educação (MEC) segue o modelo proposto pela Associação Americana de Deficiência Mental (AAMR), divulgado em 1992, segundo o qual a DM se caracteriza pelo

"funcionamento intelectual geral significativamente abaixo da média, oriundo do periodo de desenvolvimento, concomitante com limitações associadas a duas ou mais áreas da conduta adaptativa ou da capacidade do individuo em responder adequadamente às demandas da sociedade, nos seguintes aspectos: comunicação, cuidados pessoais, habilidades sociais, desempenho na família e comunidade, independência na locomoção, saúde e segurança, desempenho escolar, lazer e trabalho". (MEC, 1997, p. 27)

Este conceito serve como ponto de partida para a implementação de políticas públicas pelo governo brasileiro, que visa um atendimento especializado a estas crianças. Contudo, o próprio governo tem revelado um atendimento precário às pessoas deficientes, em diversas partes do país (MEC, 1994), apesar de salientar a importância deste tipo de atendimento desde a mais tenra idade da criança. Para o governo brasileiro, o trabalho precoce com crianças deficientes tem o objetivo de "... proporcionar à criança, nos seus primeiros anos de vida, experiências significativas para alcançar pleno desenvolvimento no seu processo evolutivo". (MEC, 1995, p. 11)

\section{$\mathbf{O}$ atendimento às crianças deficientes}

A questão do atendimento às crianças deficientes sempre foi tratada no Brasil, tanto na área governamental como na não governamental (MEC, 1994), embora ela só tenha sido incluída na política 
educacional brasileira no século XX. Mazzota (1996) analisa 0 atendimento às pessoas deficientes dividindo-o em dois períodos: o primeiro, de 1854 a 1956 , e o segundo, de 1957 a 1993 . O atendimento às pessoas deficientes mentais inicia em 1874, em um hospital da cidade de Salvador, Bahia, caracterizandose por assistência médica e não educacional. Neste primeiro período (1854 a 1956), foram criadas várias instituições e escolas de atendimento aos deficientes mentais. Até 1950, existiam quarenta estabelecimentos públicos de ensino que ofereciam algum tipo de atendimento escolar especial; destes, quatorze prestavam também atendimentos a alunos com outros tipos de deficiências.

O segundo período (1957 a 1993) é marcado por iniciativas de atendimento aos deficientes, por parte do Governo Federal, que promoveu uma série de campanhas destinadas a este fim. A primeira delas foi a Campanha para a Educação do Surdo Brasileiro - CESB, seguida da Campanha Nacional de Educação e Reabilitação de Deficientes Mentais CADEME, instituída em 1960. A CADEME, durante onze anos, estimulou e promoveu ações destinadas à educação, treinamento e reabilitação das pessoas com deficiência mental.

Na década de 70, foi criado o CENESP Centro Nacional de Educação Especial, cuja finalidade era a de "promover, em todo o território nacional, a expansão e melhoria do atendimento aos excepcionais" (Mazzotta, 1996, p. 55), sendo então extinta a CADEME. Assim, vários órgãos foram criados e extintos e, somente em 1992, foi criada a Secretaria de Educação Especial (SEESP), a qual faz parte do Ministério da Educação. Sua atribuição é "coordenar a elaboração da Política de Educação Especial do país; estimular, supervisionar e fomentar sua implantação; e assistir técnica e financeiramente sua implementação" (MEC, 1994, p. 16). Portanto, $o$ atendimento especializado, regulamentado e público às crianças deficientes passou por um processo longo e de conquistas gradativas.

$O$ atendimento a estas crianças, na esfera estadual, fica a cargo das Secretarias de Educação, cuja função é coordenar a política educacional local, levando em consideração as características regionais e de seus alunos. Das 27 Secretarias Estaduais de Educação, 25 possuem atendimento especializado não somente para pessoas deficientes mentais, mas também para aqueles que possuem condutas típicas (síndrome do autismo e psicoses infantis) e altas habilidades (superdotação). Já o atendimento na esfera municipal é mais precário, atingindo apenas $45 \%$ do total dos municípios brasileiros. Este fato se deve, em parte, ao "desconhecimento dos governantes, agravado pelos baixos níveis de conscientização da comunidade e, ainda, pelo alto custo e complexidade de que se reveste a educação especial" (MEC, 1994, p. 17). Assim, dada a necessidade deste tipo de atendimento, entendemos ser de fundamental importância mais investimentós nessa área, atingindo mais estados e municípios brasileiros.

\section{A importância da família}

Considerando que, na maioria das cidades brasileiras, as crianças deficientes ficam sem atendimento durante os seus primeiros anos de vida, a família passa a exercer um papel fundamental, na medida em que propicia o crescimento e desenvolvimento dessas crianças através de um ambiente estimulador e de interações e relações saudáveis. Segundo Kreppner (1992), a família exerce este papel, principalmente, por meio de sua rede de relações sociais.

A família constitui o primeiro universo de relações sociais da criança e "... representa, talvez, a forma de relação mais complexa e de ação mais profunda sobre a personalidade humana, dada a enorme carga emocional das relações entre seus membros" (Rey \& Martinez, 1989, p. 143). A complexa rede de relações familiares apresenta características específicas de unicidade e complexidade, constituindo um contexto em desenvolvimento (Kreppner, 1992). Portanto, essa gama de interações e relações desenvolvidas no microuniverso da família mostra que o desenvolvimento do indivíduo não pode ser isolado do desenvolvimento da família (Dessen \& Lewis, 1998).

O nascimento de um bebê é considerado um momento de transição no desenvolvimento da família, em que os relacionamentos entre seus membros são alterados, devendo os genitores se adequar ao seu novo papel (Dessen, 1997; Kreppner, 1989, 1992). Em se tratando do nascimento de uma criança com deficiência, o momento é de grande impacto para o casal, causando uma desestruturação e inter- 
rupção (em alguns casos, de forma traumática) na estabilidade familiar (Brito \& Dessen, 1999). São inúmeras as dificuldades enfrentadas pelas famílias. Por exemplo, os genitores experienciam diversos sentimentos em relação ao seu bebê com deficiência tais como raiva, rejeição, revolta, culpa etc.. Glidden \& Floyd (1997) e Negrin \& Cristante (1996) concluíram que as mães de crianças com deficiência apresentam uma maior tendência à depressão do que os pais, o que sugere que estes não experienciam a depressão ou a experienciam de forma mais branda do que as mães. A superação desses sentimentos constitui um fator preponderante para a adaptação e bemestar da família enquanto grupo que busca, de alguma forma, uma reorganização, na qual tenta incluir a criança deficiente mental como um membro pertencente àquele grupo (Taveira, 1995). Nesta fase, é fundamental o apoio mútuo entre o casal, para que a aceitação e integração da criança ocorram de modo mais fácil e saudável (Casarin, 1999).

Considerando a importância da família para a compreensão do processo de desenvolvimento de crianças com deficiência mental, este artigo analisa resumos de publicações científicas, visando apresentar um panorama geral e incentivar pesquisas na área de deficiência mental no âmbito do contexto familiar.

\section{MÉTODO}

Foi realizada uma pesquisa bibliográfica através do Psychological Abstracts e das bases de dados PsycLit e ProQuest, abrangendo o período de 1985-1999, bem como uma consulta aos Anais da
Reunião Anual de Psicologia-SBP e às seguintes revistas brasileiras: Psicologia: Teoria e Pesquisa, $\mathrm{Ca}$ dernos de Psicologia e Educação Paidéia, Psicologia: Reflexão e Crítica, Temas em Psicologia e Revista Integração. Além destas fontes, foi consultado o site da Universidade de São Paulo (sistema Dedalus).

Os trabalhos científicos foram divididos em dois grandes grupos, estrangeiros e nacionais, sendo classificados em: artigos de pesquisa; artigos teóricos e/ou de revisão de literatura; livros e capítulos de livros; resenhas e comentários críticos; teses e dissertações. Cada trabalho foi, posteriormente, categorizado de acordo com o tema investigado e agrupado em: 1) definição de deficiência mental (DM); 2) família e sua criança deficiente mental (DM);3) interações sociais a) no contexto familiar e b) em outros contextos. Os artigos de pesquisa e as teses/dissertações, por sua vez, foram também analisados e categorizados quanto ao tamanho da amostra utilizada e sua composição (se díades ou tríades), bem como quanto às técnicas e instrumentos empregados.

\section{RESULTADOS}

Foram encontrados um total de 304 trabalhos científicos na área de deficiência mental e família, isto é, artigos de pesquisa, artigos teóricos e/ ou de revisão, capítulos/livros, resenhas/comentários e teses/dissertações. A tabela 1 mostra a freqüência absoluta e o percentual de trabalhos de acordo com a sua classificação, discriminados por fonte: estrangeira e nacional.

Tabela 1: Percentual dos Tipos de Trabalhos, por Fonte (Estrangeira e Nacional)

\begin{tabular}{l|lrrrrr}
\hline Tipos de trabalhos & \multicolumn{2}{c}{ Estrangeira } & \multicolumn{2}{c}{ Nacional } & \multicolumn{2}{c}{ Total } \\
& \multicolumn{1}{c}{$N$} & $\%$ & $N$ & $\%$ & \multicolumn{1}{c}{$N$} & $\%$ \\
\hline Artigos de pesquisa & 106 & 41,7 & 10 & 20 & 116 & 38,0 \\
Artigos teóricos/revisão & 53 & 20,8 & 10 & 20 & 63 & 21,0 \\
Capítulos/livros & 55 & 21,6 & 07 & 14 & 62 & 20,4 \\
Resenhas/Comentários/Outros & 17 & 6,8 & 05 & 10 & 22 & 7,2 \\
Teses/Dissertações & 19 & 7,5 & 12 & 24 & 31 & 10,1 \\
Não identificado & 04 & 1,6 & 06 & 12 & 10 & 3,3 \\
\hline Total & 254 & 100 & 50 & 100 & 304 & 100 \\
\hline
\end{tabular}

Paidéia, FFCLRP-USP, Rib. Preto, ago/dez/2000. 
Há uma predominância de artigos de pesquisa, seguidos por artigos teóricos/revisão e por uma minoria de resenhas/comentários. Conforme esperado, nas publicações estrangeiras, há predominância de artigos de pesquisa, seguidos de livros/capítulos de livros; porém, em se tratando de publicações nacionais, as teses/dissertações constituem maioria, seguidas por artigos teóricos/revisão e artigos de pesquisa.

\section{Os artigos, livros e capítulos de livros}

Os artigos de pesquisas e teóricos, os livros e capítulos de livros foram agrupados por tema investigado. A maioria (41\%) dos artigos trata de temas sobre o "conceito de DM", enquanto que $33,7 \%$ referem-se a aspectos gerais relacionados à "família e sua criança DM". Os trabalhos sobre as "interações familiares" $(18,7 \%)$ e em outros contextos $(6,6 \%)$ constituem minoria dos temas investigados. $\mathrm{E}$ importante ressaltar que o tema "interações familiares" é um tema investigado em apenas $20 \%$ dos artigos estrangeiros e em $10,5 \%$ dos nacionais. A figura 1 mostra o percentual dos trabalhos, excluídas as teses/dissertações, por tema investigado e fonte consultada: se estrangeira ou nacional.
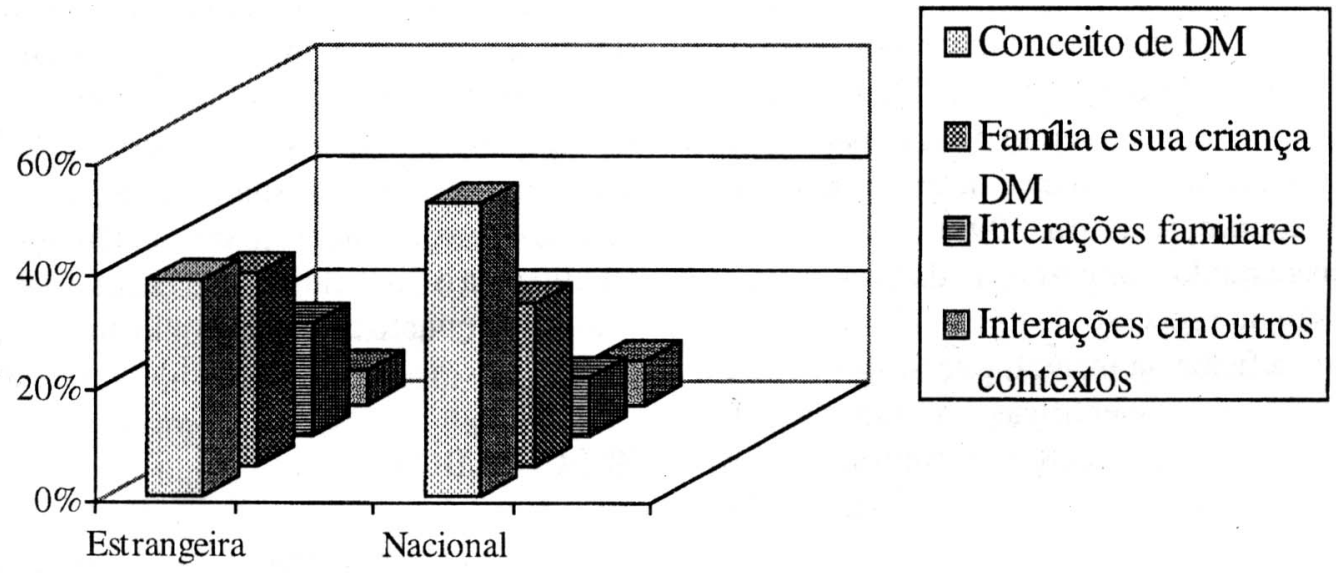

Figura 1: Percentual de artigos e livros/capítulos de livros, por tema investigado e fonte consultada.

Para cada um dos temas mencionados, foram criadas subcategorias, com o objetivo de fornecer uma visão mais detalhada do que tem sido investigado e publicado em fontes estrangeiras e nacio- nais. As subcategorias do primeiro grupo a ser descrito, "conceito de deficiência mental", são apresentadas na tabela 2.

Tabela 2: Percentual de Assuntos Investigados sobre o Tema "Conceito de DM", em Trabalhos Estrangeiros e Nacionais.

\begin{tabular}{l|rrrr|rrr}
\hline \multirow{2}{*}{ Assuntos Investigados } & \multicolumn{4}{|c|}{ Fonte } & \multicolumn{3}{c}{} \\
& \multicolumn{3}{|c|}{ Estrangeira } & Nacional & \multicolumn{2}{c}{ Total Geral } \\
& $N$ & $\%$ & $N$ & $\%$ & $N$ & $\%$ \\
\hline Revisão de literatura emDM & 10 & 11 & -- & -- & 10 & 8,9 \\
Conceituação e classificação de DM & 58 & 63 & 17 & 85 & 75 & 67,0 \\
História da DM & 02 & 2 & -- & -- & 02 & 1,7 \\
DM e desenvolvimento & -- & -- & 01 & 5 & 01 & 1,0 \\
Outros & 22 & 24 & 02 & 10 & 24 & 21,4 \\
\hline Total & 92 & 100 & 20 & 100 & 112 & 100 \\
\hline
\end{tabular}


$\mathrm{O}$ assunto mais investigado neste agrupamento refere-se à "conceituação e classificação de DM" (fonte estrangeira $=63 \%$; nacional $=85 \%$ ). A "revisão de literatura" e "história da DM" são assuntos publicados em fontes estrangeiras, embora não nas nacionais consultadas.

A tabela 3 mostra que, em função da grande variedade de assuntos investigados sobre "família e sua criança DM", a maioria dos trabalhos deste tema foi classificado na categoria "outros" (38\%). No en- tanto, o "estresse em famílias com criança DM" é o assunto mais investigado, seguido pelo "efeito da criança DM no funcionamento da família" e pelas "atitudes/percepções e estado emocional dos genitores". Os artigos estrangeiros, em sua maioria, investigam o "estresse" parental e também o "efeito da criança DM no funcionamento da família". Nos trabalhos brasileiros, há predominância de estudos sobre a "atitude/percepção e estados emocionais dos genitores em relação à criança DM".

Tabela 3: Percentual de Assuntos Investigados sobre o Tema "Família e sua Criança DM", em Trabalhos Estrangeiros e Nacionais

\begin{tabular}{|c|c|c|c|c|c|c|}
\hline \multirow{3}{*}{ Assuntos Investigados } & \multicolumn{4}{|c|}{ Fonte } & \multirow{2}{*}{\multicolumn{2}{|c|}{ Total }} \\
\hline & \multicolumn{2}{|c|}{ Estrangeira } & \multicolumn{2}{|c|}{ Nacional } & & \\
\hline & $N$ & $\%$ & $N$ & $\%$ & $N$ & $\%$ \\
\hline Atitude/percepção e estado emocional dos genitores & 08 & $\overline{9,8}$ & 03 & 27,3 & 11 & 12,0 \\
\hline Características da família que possui criança DM & 07 & 8,6 & -- & -- & 07 & 7,6 \\
\hline Efeito da criança DM no funcionamento da família & 11 & 13,5 & -- & - & 11 & 12,0 \\
\hline Adaptação da família à criança DM & 10 & 12,3 & -- & -- & 10 & 10,9 \\
\hline Apoio social às famílias de crianças DM & 04 & 5,0 & -- & -- & 04 & 4,3 \\
\hline Estresse em famílias com criança DM & 12 & 15,0 & -- & -- & 12 & 13,0 \\
\hline DM e Sexualidade & -- & -- & 02 & 18,2 & 02 & 2,2 \\
\hline Outros & 29 & 35,8 & 06 & 54,5 & 35 & 38,0 \\
\hline Total & 81 & 100 & 11 & 100 & 92 & 100 \\
\hline
\end{tabular}

No agrupamento "interações sociais", de um total de 69 trabalhos, 62 são produções estrangeiras e apenas sete são nacionais. Deste total, $74 \%$ referem-se às "interações no contexto familiar", enquanto $26 \%$ abordam as "interações em outros contextos" que não a família. Em relação a este último, há uma predominância de trabalhos desenvolvidos no contexto escolar", tanto em estudos es-

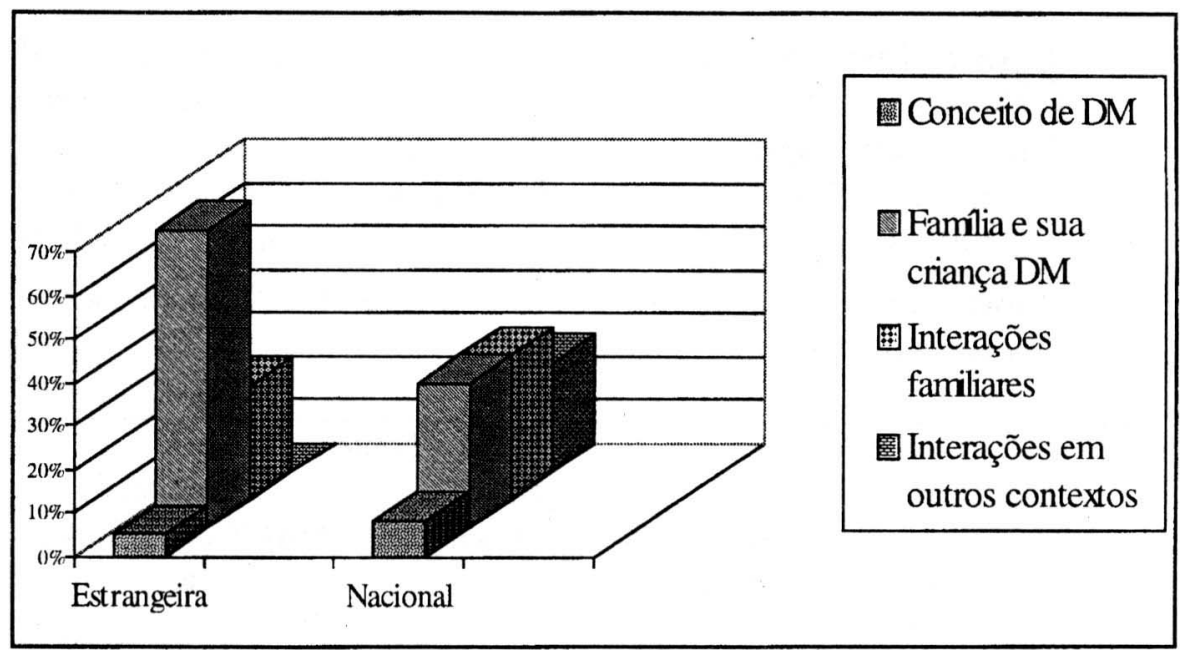
trangeiros $(82 \%)$ como em nacionais $(100 \%)$.

\section{As teses e dissertações}

A figura 2 mostra o percentual de teses/dissertações estrangeiras e nacionais, com especificação dos temas investigados mais freqüentemente.

Figura 2: Percentual de teses/dissertações estrangeiras e nacionais, segundo os temas investigados.

Conforme pode ser observado, há uma predominância do tema "família e criança DM" $(68,5 \%)$, seguido por "interações familiares" $(26,3 \%)$, em se

Paidéia, FFCLRP-USP, Rib. Preto, ago/dez/2000. 
tratando de teses/dissertações estrangeiras. Já, a maioria das teses nacionais investiga, principalmente, o tema "interações sociais" $(58,3 \%)$, das quais $33,3 \%$ referem-se às "interações familiares". O tema "família e sua criança DM" também contribui com um percentual significativo de teses/dissertações, no cenário nacional $(33,3 \%)$.

Com relação às subcategorias de assuntos investigados nas teses/dissertações estrangeiras e nacionais, a tabela 4 mostra que os assuntos mais investigados são o "relacionamento entre irmãos" e "atitude/percepção e estado emocional dos genitores". As teses/dissertações estrangeiras, em sua maioria, focalizam o "relacionamento entre irmãos" as "características da família que possui uma criança DM" e o "estresse em tais famílias". As teses/ dissertações brasileiras, por sua vez, focalizam mais freqüentemente as "interações criança-mãe", as "interações em outros contextos" e a "atitude/percepção e estado emocional dos genitores".

Tabela 4: Percentual de Assuntos Investigados em Teses/Dissertações Estrangeiras e Nacionais

\begin{tabular}{|c|c|c|c|c|c|c|}
\hline \multirow{3}{*}{ Assuntos investigados } & \multicolumn{4}{|c|}{ Fonte } & \multirow{2}{*}{\multicolumn{2}{|c|}{ Total }} \\
\hline & \multicolumn{2}{|c|}{ Estrangeira } & \multicolumn{2}{|c|}{ Nacional } & & \\
\hline & $N$ & $\%$ & $N$ & $\%$ & $N$ & $\%$ \\
\hline Atitude/percepção e estado emocional dos genitores & 02 & 10,5 & 03 & 25,0 & 05 & 16,1 \\
\hline Características da família que possui criança DM & 03 & 16,0 & -- & --- & 03 & 9,7 \\
\hline Estresse em famílias com criança DM & 03 & 16,0 & --- & --- & 03 & 9,7 \\
\hline Interações criança-mãe & --- & -.. & 04 & 33,3 & 04 & 13,0 \\
\hline Relacionamento entre irmãos & 05 & 26,0 & -- & -- & 05 & 16,0 \\
\hline Interações em outros contextos & --- & $-\cdots$ & 03 & 25,0 & 03 & 9,7 \\
\hline Outros & 06 & 31,5 & 02 & 16,7 & 08 & 25,8 \\
\hline Total & 19 & 100 & 12 & 100 & 31 & 100 \\
\hline
\end{tabular}

\section{Características das amostras}

Para a caracterização da amostra utilizada nos trabalhos, foram consultados os resumos dos artigos de pesquisa e de teses/dissertações publicados no es- trangeiro e no Brasil. Foram identificados não somente o número de sujeitos, como também os participantes das interações quando o foco da análise eram as interaçōes sociais. A tabela 5 apresenta o tamanho da amostra utilizada nos trabalhos consultados.

Tabela 5: Percentual de Artigos de Pesquisa e Teses/Dissertações Estrangeiras e Nacionais, Considerando o Tamanho da Amostra Empregada.

\begin{tabular}{|c|c|c|c|c|c|c|c|c|c|c|c|c|}
\hline \multirow{4}{*}{$\begin{array}{c}\text { Tamanho da } \\
\text { Amostra }\end{array}$} & \multicolumn{8}{|c|}{ Fonte } & \multicolumn{4}{|c|}{ Total } \\
\hline & \multicolumn{4}{|c|}{ Estrangeira } & \multicolumn{4}{|c|}{ Nacional } & & & & \\
\hline & \multicolumn{2}{|c|}{$\begin{array}{l}\text { Artigos de } \\
\text { pesquisa }\end{array}$} & \multicolumn{2}{|c|}{ Teses } & \multicolumn{3}{|c|}{$\begin{array}{c}\text { Artigos de } \\
\text { pesquisa }\end{array}$} & Teses & \multicolumn{2}{|c|}{$\begin{array}{l}\text { Artigos de } \\
\text { Pesquisa }\end{array}$} & \multicolumn{2}{|c|}{ Teses } \\
\hline & $N$ & $\%$ & $N$ & $\%$ & $N$ & $\%$ & $N$ & $\%$ & $N$ & $\%$ & $N$ & $\%$ \\
\hline Menos que 30 & 22 & 20,7 & $\overline{02}$ & 10,5 & 03 & 30 & 06 & 50,0 & 25 & 21,5 & 08 & 25,8 \\
\hline Entre 30 e 60 & 35 & 33,0 & 07 & 37,0 & 03 & 30 & 01 & 8,3 & 38 & 32,8 & 08 & 25,8 \\
\hline Entre 61 e 90 & 15 & 14,2 & 01 & 5,2 & -- & - & -- & - & 15 & 13,0 & 01 & 3,2 \\
\hline Entre 91 e 120 & 09 & 8,5 & 01 & 5,2 & -- & - & -- & -- & 09 & 7,7 & 01 & 3,2 \\
\hline Acima de 120 & 14 & 13,2 & 02 & 10,5 & -- & -- & -- & -- & 14 & 12,0 & 02 & 6,5 \\
\hline Não identificado & 11 & 10,4 & 06 & 31,6 & 04 & 40 & 05 & 41,7 & 15 & 13,0 & 1 & 35,5 \\
\hline Total & 106 & 100 & 19 & 100 & 10 & 100 & 12 & 100 & 116 & 100 & 31 & 100 \\
\hline
\end{tabular}


Em geral, as pesquisas e as teses/dissertações utilizam uma amostra entre 30 e 60 sujeitos/ famílias. Esta tendência é mantida nas pesquisas estrangeiras e nacionais. Porém, nos trabalhos brasileiros, destacam-se amostras compostas por menos de 30 sujeitos/famílias, em contraposição aos trabalhos estrangeiros que utilizam amostras acima de 91 sujeitos. No Brasil, nenhum dos trabalhos consultados emprega amostras superiores a 60 sujeitos/famí- lias. Com relação às teses/dissertações estrangeiras, a maioria utiliza entre 30 e 60 sujeitos/famílias; porém, nas teses brasileiras, o emprego de menos que 30 sujeitos/famílias é mais freqüente.

A figura 3 mostra quem são os participantes da amostra de artigos e teses/dissertações estrangeiras e nacionais que tinham a interação social como unidade de análise: criança-mãe (C-M), criança-irmão (C-I) e criança-mãe-pai (C-M-P).

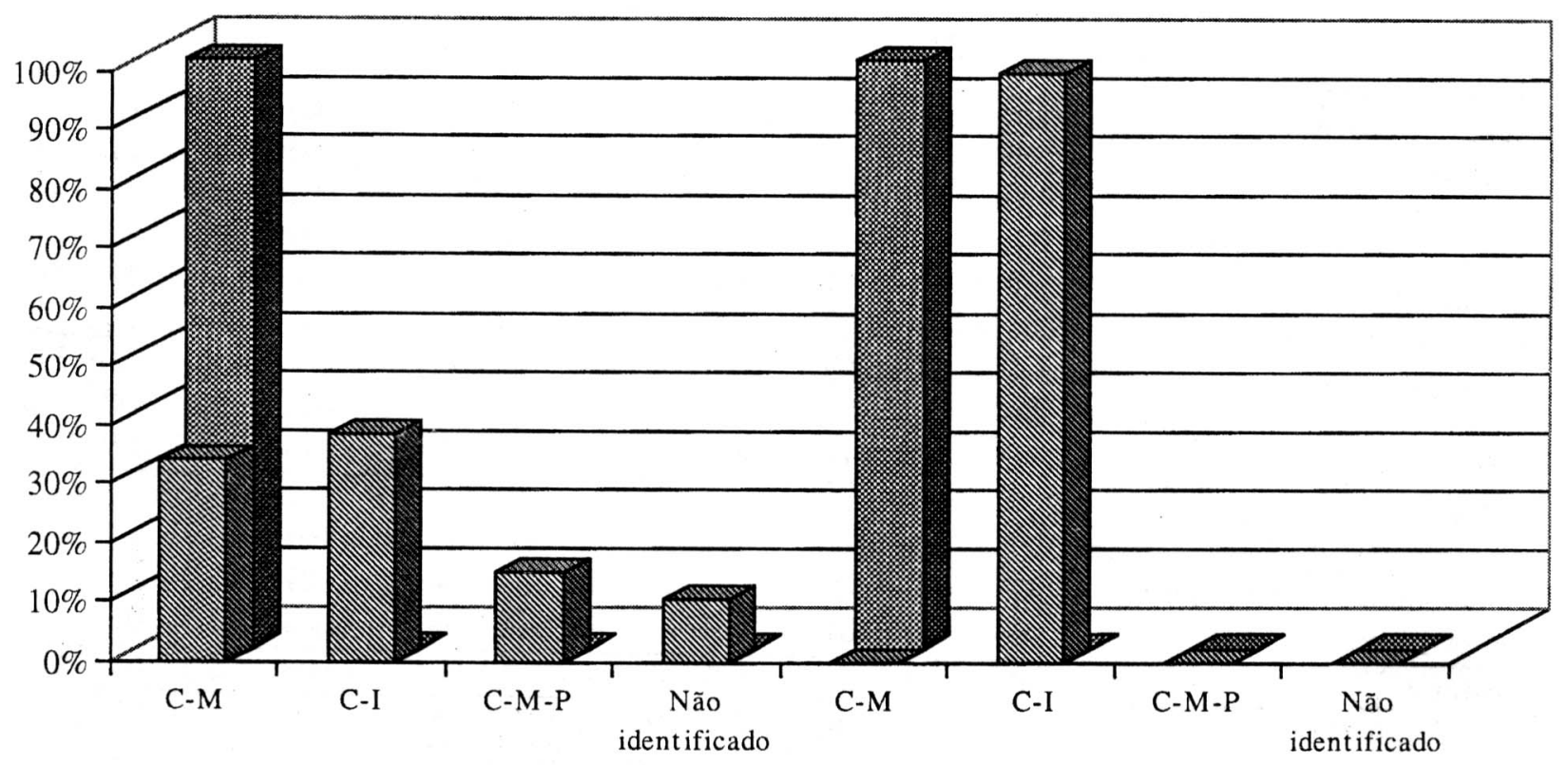

Artigos

Teses/Dissertações

Figura 3: Percentual de artigos e teses/dissertações sobre interações familiares com especificação dos participantes da amostra.

Conforme pode ser observado, a maioria dos trabalhos analisou dados de díades $(78,3 \%)$. A díade criança-mãe foi a mais estudada nas pesquisas brasileiras, enquanto as pesquisas estrangeiras estudaram a díade criança-irmão. A participação do pai só foi destacada em estudos estrangeiros que envolviam, também, a participação da mãe.

\section{As técnicas utilizadas}

Com relação às técnicas, verifica-se uma Paidéia, FFCLRP-USP, Rib. Preto, ago/dez/2000. predominância de pesquisa que fazem uso de apenas uma técnica Dos artigos de pesquisas que utilizam apenas uma técnica, a observação e o questionário são os mais freqüentemente usados, enquanto nas teses/ dissertações predominam a observação e as entrevistas. Uma minoria de artigos utiliza duas técnicas enquanto que, nas teses/dissertações, este número é um pouco maior. Estudos que utilizam três ou mais técnicas para a coleta de dados são menos freqüentes ainda (ver tabela 6). 
Tabela 6: Percentual de Trabalhos de Acordo com as Técnicas Utilizadas para a Coleta de Dados

\begin{tabular}{|c|c|c|c|c|c|c|c|c|c|c|c|c|}
\hline \multirow{3}{*}{ Técnicas de coleta de dados } & \multicolumn{8}{|c|}{ Fonte } & \multicolumn{4}{|c|}{ Total } \\
\hline & \multirow{2}{*}{\multicolumn{2}{|c|}{$\begin{array}{l}\text { Estrangeira } \\
\text { Artigos de } \\
\text { Pesquisa } \\
N \%\end{array}$}} & \multicolumn{2}{|c|}{ Teses } & \multicolumn{3}{|c|}{$\begin{array}{l}\text { Nacional } \\
\text { Artigos de } \\
\text { Pesquisa }\end{array}$} & & \multicolumn{2}{|c|}{$\begin{array}{l}\text { Artigos de } \\
\text { Pesquisa }\end{array}$} & \multicolumn{2}{|c|}{ Teses } \\
\hline & & & $N$ & $\%$ & $N$ & $\%$ & $N$ & $\%$ & $N$ & $\%$ & $N$ & $\%$ \\
\hline Uma Técnica & & & & & & & & & & & & \\
\hline Observação & 15 & 14,2 & 02 & 10,5 & 01 & 10 & 02 & 16,6 & 16 & 13,7 & 04 & 13 \\
\hline Questionário & 11 & 10,4 & -- & -- & 02 & 20 & -- & -- & 13 & 11,2 & -- & -- \\
\hline Escala & 08 & 7,5 & 03 & 16,0 & - & -- & - & -- & 08 & 7,0 & 03 & 10 \\
\hline Entrevista & 07 & 6,6 & 02 & 10,5 & 04 & 40 & 02 & 16,6 & 11 & 9,5 & 04 & 13 \\
\hline Outras & 03 & 2,8 & - & - & - & -- & -- & - & 03 & 2,6 & -- & -- \\
\hline Subtotal & 44 & 41,5 & 07 & 37 & 07 & 70 & 04 & 33,2 & 51 & 44 & 11 & 36 \\
\hline Duas Técnicas & & & & & & & & & & & & \\
\hline Survey/entrevista & 02 & 1,9 & -- & - & - & -- & -- & -- & 02 & 1,7 & -- & -- \\
\hline Entrevista/observação & 05 & 4,7 & -- & -- & - & - & 02 & 16,8 & 05 & 4,3 & 02 & 7,0 \\
\hline Escala/observação & 01 & 0,9 & - & -- & - & -- & -- & -- & 01 & 0,9 & -- & - \\
\hline Sociograma/observação & 01 & 0,9 & -- & -- & -- & -- & -- & -- & 01 & 0,9 & -- & -- \\
\hline Escala/entrevista & -- & -- & 02 & 10,5 & -- & -- & -- & -- & -- & -- & 02 & 7,0 \\
\hline Escala/checklist & -- & - & 01 & 5,2 & - & -- & -- & -- & - & -- & 01 & 3,3 \\
\hline Escala/questionário & - & -- & 02 & 10,5 & -- & -- & - & -- & -- & -- & 02 & 7,0 \\
\hline Outras & 04 & 3,8 & 02 & 10,5 & $5-$ & -- & -- & - & 04 & 3,4 & 02 & 7,0 \\
\hline Subtotal & 13 & 12,2 & 07 & 36,7 & $7-$ & -- & 02 & 16,8 & 13 & 11,2 & 09 & 31,3 \\
\hline Três ou mais técnicas & & & & & & & & & & & & \\
\hline Checklist/escala/ Questionário & 01 & 1,0 & -- & -- & -- & -- & -- & -- & 01 & 0,9 & -- & -- \\
\hline Sociograma/escala/Observação & 01 & 1,0 & -- & -- & -- & -- & -- & -- & 01 & 0,9 & -- & -- \\
\hline Outras & 03 & 2,8 & 01 & 5,3 & - & -- & -- & - & 03 & 2,6 & 01 & 3,3 \\
\hline Subtotal & 05 & 4,8 & 01 & 5,3 & - & -- & - & -- & 05 & 4,3 & 01 & 3,3 \\
\hline Não identificado & 44 & 41,5 & 04 & 21 & 03 & 30 & 06 & 50 & 47 & 40,5 & 09 & 29,4 \\
\hline TOTAL & 106 & 100 & 19 & 100 & 10 & 100 & 12 & 100 & 116 & 100 & 31 & 100 \\
\hline
\end{tabular}

\section{DISCUSSÃO}

A análise efetuada com base no levantamento bibliográfico, embora não exaustiva, proporcionou uma visão geral a respeito da produção científica, tanto estrangeira como nacional, no que tange à família e deficiência mental. É preciso ressaltar as limitações decorrentes das fontes consultadas, particularmente no Brasil, onde muitas das revistas na área de psicologia não estão indexadas, além de não estarem disponíveis nas bibliotecas. Portanto, a análise aqui apresentada deve ser vista apenas como uma tendência geral da produção na área.

Os resultados mostram uma predominância de artigos, tanto estrangeiros como nacionais, que 20 tratam do conceito de deficiência mental, da família e sua criança DM e também de suas interações sociais. $O$ fato de haver um percentual maior de artigos sobre o conceito de DM deve-se, em parte, a certa confusão do próprio conceito e, conseqüentemente, da necessidade de melhor entender os aspectos que caracterizam a DM e de identificar os fatores mais relevantes para a sua constituição. No entanto, parece não haver um interesse muito grande pelo tema "conceito de DM" em se tratando de trabalhos de teses/dissertações. Isto é compreensível, na medida em que há uma tradição sobre a natureza empírica de tais trabalhos. De qualquer forma, é imprescindível que os pesquisadores tenham clareza sobre o conceito de DM, uma vez que este é fundamental para o

Paidéia, FFCLRP-USP, Rib. Preto, ago/dez/2000. 
planejamento de pesquisas na área.

Por outro lado, verifica-se, também, uma preocupação crescente com o tema "família e sua criança deficiente mental". Esta preocupação está centrada no "bem-estar psicológico" das famílias, especialmente dos genitores. Assim, aspectos tais como estresse parental, satisfação marital e depressão são priorizados em tais estudos, particularmente em artigos de pesquisa e teses/dissertações estrangeiras. As teses/dissertações nacionais enfatizam não somente o tema "família e sua criança" como também o tema "interações sociais". Dentre este último, destacam-se as "interações familiares" desenvolvidas pela díade mãe-criança, enquanto as teses/dissertações estrangeiras focalizam as interações e relações entre irmãos.

Os estudos envolvendo a participação do pai ainda são muito raros nesta área; porém, já se pode perceber algumas pesquisas estrangeiras incluindo os pais, acompanhando a tendência geral na área de desenvolvimento humano que é a de incluir não só o pai nas análises, mas também, de considerar a família como uma unidade de análise (Dessen \& Lewis, 1998). Quanto a isto, gostaríamos de lembrar a defasagem natural entre textos teoricos que norteiam os pesquisadores no sentido de incluir todos os membros familiares em um único planejamento de pesquisa e a sua efetiva implementação. É preciso envidar esforços para incluir também o pai e os irmãos em projetos de pesquisa brasileiros, apesar das dificuldades metodológicas inerentes.

O papel desempenhado pelo pai dentro do grupo familiar é considerado importante para o desenvolvimento da criança, trazendo contribuições únicas que se diferenciam daquelas da mãe. Além disso, para se compreender a família, em um nível relacional, é necessário estudar também os estilos de interação e relação construídos entre o pai e sua criança (Lewis \& Dessen, 1999). Lamb e Billings (1997) afirmam que há de se reconhecer que as pesquisas sobre a participação dos pais de crianças com deficiência apresentam contradições e problemas metodológicos. Segundo estes autores,

"pais de crianças com deficiência podem ter estressores e necessidades muito diferentes daquelas de mães nestas mesmas famílias e de pais em famílias com crianças sem deficiência. As preocu- pações tradicionais com relação ao sucesso, aceitação social e independência financeira de suas crianças levam os pais a experienciarem o diagnóstico de deficiência do filho como uma crise mais intensa do que para as mães". ( p. 189)

Ao mesmo tempo em que se percebe a necessidade de inclusão dos pais nas amostras, há também um debate acerca da reconsideração do papel das crianças em pesquisas sobre famílias. Hogan, Etz e Tudge (1998) ressaltam a necessidade de incluir as próprias crianças como uma das fontes de informação. Estes autores afirmam que a criança tem um papel ativo no ambiente familiar, não sendo uma mera receptora de influências do ambiente. Ela influencia e é influenciada pelo ambiente familiar, havendo, então, uma troca dialética entre ambos. Nas pesquisas sobre família, em geral, os genitores "falam" por suas crianças, especialmente a mãe, que também fala pelo pai. Essa tendência foi constatada na literatura consultada, sendo a figura materna a principal informante, na maioria das pesquisas. Assim, seria interessante incluir a criança DM, não somente como participante da pesquisa, mas também como respondente principal a respeito dos seus próprios pensamentos, do que gosta de fazer, com quem gosta etc., quando possível, evidentemente. Além disso, é fundamental incluir também os irmãos dessas crianças, uma vez que eles compartilham o mesmo ambiente, podendo contribuir para o crescimento $\mathrm{e}$ desenvolvimento da criança DM.

Em síntese, as fontes consultadas revelam que a família não vem sendo analisada como um todo, isto é, enquanto um grupo distinto, que possui características próprias e desenvolve interações contínuas entre seus diversos subsistemas diádicos, triádicos ou poliádicos. É preciso ter em mente que a família não é estática, ela muda constantemente e, desta forma, deve se adaptar às demandas advindas de cada um dos membros que a compõe (K. Kreppner, comunicação pessoal, 7 de outubro de 1999), principalmente, em se tratando de crianças com deficiência mental. Além disso, a família tradicional, composta por genitores casados e filhos, não pode ser considerada como a única e/ou principal forma de constituição da família. Segundo Petzold (1996), há diversas formas de família, tais como casais amasiados, casais homossexuais, famílias sucessivas 
etc., que precisam ser levadas em consideração nos planejamentos de pesquisa.

No tocante ao tamanho da amostra empregada nas pesquisas, verifica-se um percentual relativamente alto de amostras acima de 91 sujeitos nas pesquisas estrangeiras, enquanto que, no Brasil, a situação é oposta. Essa tendência parece refletir a tradição brasileira, principalmente em se tratando da área de desenvolvimento humano, de implementar projetos com métodos e instrumentos detalhados, obtendo, assim, uma quantidade muito grande de informações em detrimento de uma amostra estatisticamente significativa. Contudo, este quadro tem mudado gradualmente na direção de se empregar amostras maiores, talvez em decorrência da valorização de tratamentos estatísticos aos nossos dados. É preciso lembrar que o percentual de trabalhos cujo tamanho da amostra não foi identificado, tanto em se tratando das fontes estrangeiras quanto das nacionais; mostra que os "abstracts" e os resumos não estão sendo escritos com o cuidado necessário, considerando que tais informações não constavam das referidas fontes.

Com relação ao uso de técnicas para a coleta de dados, observou-se a predominância de apenas uma. Os dados apontam para maior frequiência na utilização da observação do comportamento, a qual constitui uma técnica adequada para o estudo das interações sociais, particularmente quando um dos sujeitos apresenta algum tipo de deficiência. Os estudos que utilizam três ou mais técnicas ainda são raros, hoje, apesar de a literatura estar apontando a necessidade da combinação de técnicas para melhor compreender o assunto estudado. Segundo Dessen e Lewis (1998), a combinação de técnicas proporciona melhor compreensão do fenômeno, principalmente no caso das interações sociais.

.É fundamental ressaltar, ainda, a importância de se estudar as interações da criança DM com sua família orientados pela abordagem ecológica, a qual focaliza não somente o grupo familiar como um contexto de influência no desenvolvimento da criança, mas também os demais contextos. Segundo Bronfenbrenner (1996), o ambiente está estruturado em níveis, havendo interconexões entre eles e, nesta perspectiva, a criança em desenvolvimento está em contato com diversos ambientes como a creche, a escola, o clube, a vizinhança etc., influenciando e recebendo influência de todos eles e não apenas de seu grupo familiar. Conhecer como se processam essas influências e quais as suas implicações para o desenvolvimento da criança, especialmente da criança com deficiência mental, constitui um desafio para os pesquisadores.

Em síntese, há necessidade de se estudar as famílias de criançăs com deficiência mental conhecendo a sua dinâmica e como se processam as interações e relações entre os seus diferentes subsistemas: diádicos, triádicos e poliádicos. Mas não basta somente estudar a família como um grupo, é preciso também focalizá-la inserida dentro de um contexto ecológico mais amplo, se quisermos, de fato, compreender a sua dinâmica e funcionamento. Com relação a este aspecto, muito ainda tem que ser feito em se tratando de famílias com crianças que apresentam algum tipo de deficiência.

\section{Referências Bibliográficas}

Aranha, M.S.F. (1991). A interação social e o desenvolvimento de relações interpessoais do deficiente em ambiente integrado. Tese de Doutorado, Universidade de São Paulo, São Paulo.

Aranha, M.S.F. (1995). Integração social do deficiente: análise conceitual e metodológica. Temas em Psicologia, 2, 63-70.

Brito, A.M.W. \& Dessen, M.A. (1999). Crianças surdas e suas famílias: um panorama geral. $P$ sicologia: Reflexấo e Crítica, 12, 429-445.

Bronfenbrenner, U. (1996). A ecologia do desenvolvimento humano: experimentos naturais e planejados. (M.A. Veríssimo, Trad.) Porto Alegre: Artes Médicas. (Trabalho original publicado em 1979)

Casarin, S. (1999). Aspectos psicológicos da síndrome de Down. Em J.S. Schwartzman (Org.), Síndrome de Down ( pp. 263-285). São Paulo: Mackenzie.

Dessen, M.A. (1997). Desenvolvimento familiar: transição de um sistema triádico para poliádico. Temas em Psicologia, 3, 51-61.

Dessen, M.A. \& Lewis, C. (1998). Como estudar a "família" e o "pai"? Cadernos de Psicologia e 
Educação Paidéia, 8 (14/15), 105-121.

Glat, R. (1995). Integração dos portadores de deficiências: uma questão psicossocial. Temas em Psicologia, 2, 89-94.

Glidden, L.M. \& Floyd, F.J. (1997). Disaggregating parental depression and family stress in assessing families of children with developmental disabilities: A multisample analysis. American Journal on Mental Retardation, 102, 250-266.

Hogan, D.M., Etz, K.E. \& Tudge, J. (1998). Reconsidering the role of children in family research: Conceptual and metodological issues. Em C. Shehan (Org.), Contemporary perspectives on family research: Vol. 1 Through the eyes of the child: Re-visioning children as active agents of family life (pp. 93-105). Stamford: JAI Press.

Kreppner, K. (1989). The interplay between individual and family development: Some results from a 7-year longitudinal study. Em M.A. Luscz \& T. Nettelbeck (Orgs.), Psychological development: Perspectives across the life-span (pp. 25-36). North-Holland: Elsevier Science Publishers.

Kreppner, K. (1992). Development in a developing context: Rethinking the family's role for children's development. Em L.T. Winegar \& J. Valsiner (Orgs.), Children's development within social context (pp. 161-179). Hillsdale: Lawrence Erlbaum.

Lamb, M.E. \& Billings, L.A.L. (1997). Fathers of children with special needs. Em M.E. Lamb (Org.), The role of the father (pp. 179-190). New York: John Wiley \& Sons.

Lewis, C. \& Dessen, M.A. (1999). O pai no contexto familiar. Psicologia: Teoria e Pesquisa, 15, 916.

Mazzota, M.J.S. (1996). Educação especial no Brasil: história e políticas públicas. São Paulo: Cortez.

MEC - Ministério da Educação do Brasil (1994). Educação especial no Brasil. Brasília, DF: Autor.

MEC - Ministério da Educação do Brasil (1995).

Paidéia, FFCLRP-USP, Rib. Preto, ago/dez/2000.
Diretrizes educacionais sobre estimulação precoce. Brasília, DF: Autor.

MEC - Ministério da Educação do Brasil (1997). Educação especial: deficiência mental. Brasília, DF: Autor.

Negrin, N.S. \& Cristante, F. (1996). Resources and stress in parents with a mentally retarded child: A quantitative approach. Em M. Cusinato (Org.), Research on family resources and needs across the world (pp. 493-506). Milão: LED-Edicioni Universitarie.

Nunes, L.R.O.P. \& Ferreira, J.R. (1994). Deficiência mental: o que as pesquisas brasileiras têm revelado. Em E.M.L.S. Alencar (Org.), Tendências e desafios da educação especial (pp. 50-81). Brasília: SEESP.

Pessoti, I. (1984). Deficiência mental: da superstição à ciência. São Paulo: Editora da Universidade de São Paulo.

Petzold, M. (1996). The psychological definition of "the family". Em M. Cusinato (Org.), Research on family resources and needs across the world (pp. 25-44). Milão: LED -Edicioni Universitarie.

Rey, F.G. \& Martinez, A.M. (1989).La personalidad: su educadión y desarrollo. La Habana: Editorial Pueblo y Educación.

Schwartzman, J.S. (1999a). Histórico. Em J.S. Schwartzman (Org.), Síndrome de Down (pp. 315). São Paulo: Mackenzie.

Schwartzman, J.S. (1999b). Generalidades. Em J.S. Schwartzman (Org.), Síndrome de Down (pp. 1631). São Paulo: Mackenzie.

Taveira, R.M.T. (1995). Privação auditiva precoce em crianças portadoras de sindrome de Down e suas implicações para o desenvolvimento da linguagem. Dissertação de Mestrado, Universidade de Brasília, Brasília. 